\title{
Las otras familias. Representaciones sobre parentalidades lesbianas y gays en dos series documentales argentinas ${ }^{1}$ The other families. Representations of lesbian and gay parentalities in two Argentine documentary series
}

Alejandro Alfredo Rafael Silva Fernández Consejo Nacional de Investigaciones Científicas y Técnicas (CONICET)

\section{Referencia de este artículo}

Silva Fernández, Alejandro Alfredo Rafael (2020). Las otras familias. Representaciones sobre parentalidades lesbianas y gays en dos series documentales argentinas. adComunica. Revista Científica del Estrategias, Tendencias e Innovación en Comunicación, (19), 143-164. DOI: http://dx.doi.org/10.6035/2174-0992.2020.19.9.

\section{Palabras clave}

Representaciones sociales; parentalidades lesbianas y gays; identidades; documentales audiovisuales.

\section{Keywords}

Social representations; Lesbian and Gay Parentalities; Identities; Audiovisual Documentaries.

\section{Resumen}

El trabajo tiene como objetivo indagar sobre las parentalidades lesbianas y gays que cobran visibilidad en producciones documentales argentinas estrenadas luego de la aprobación de la Ley de Matrimonio Igualitario. El corpus estará compuesto por los capítulos Familias diversas, Matrimonio Igualitario y Diversidad en el barrio de la serie documental Salida de Emergencia (2011) de Mathieu Orcel y La maternidad de Caleidoscopio: Diversos colores, los mismos derechos (2011) de María Victoria 
Glazmann. La metodología utilizada es cualitativa, retoma elementos de la semiótica del cine y los análisis contrastivo y textual. Se parte de la hipótesis de que la puesta en pantalla de la diversidad familiar toma parte en la construcción del género y se constituye como un espacio que habilita la circulación testimonial, a la vez que genera procesos de auto-representación y permite tensionar la hipotética inexistencia de otros modelos familiares, construida por la tradición audiovisual del país.

\begin{abstract}
The work aims to investigate the lesbian and gay parentalities that gain visibility in Argentine documentary productions released after the approval of the Law of Equal Marriage. The corpus is composed of the chapters Familias diversas, Matrimonio Igualitario and Diversidad en el barrio of the documentary series Salida de Emergencia (2011) by Mathieu Orcel and La maternidad of Caleidoscopio: Diversos colores, los mismos derechos (2011) by María Victoria Glazmann. The methodology used is qualitative, picks up elements of film semiotics and contrastive and textual analysis. It is based on the hypothesis that the display of family diversity takes part in the construction of gender and is constituted as a space that enables the testimonial circulation, while generating self-representation processes and allows stressing the hypothetical absence from other family models, built by the country's audiovisual tradition.
\end{abstract}

\title{
Autor
}

Alejandro Alfredo Rafael Silva Fernández es Becario Doctoral del Consejo Nacional de Investigaciones Científicas y Técnicas (CONICET), cursó el Doctorado en Comunicación de la Universidad Nacional de La Plata (UNLP) y Licenciado en Comunicación Social y Técnico en Periodismo egresado de la Universidad Nacional del Nordeste (UNNE). En investigación participa de proyectos de investigación aprobados por la Secretaría General de Ciencia y Técnica de la UNNE con interés en el análisis de producciones audiovisuales de carácter regional y nacional. Posee producciones publicadas en revistas nacionales e internacionales sobre análisis audiovisual de series documentales sobre diversidad sexo-genérico-identitaria. En docencia, es Jefe de Trabajos Prácticos de la asignatura Comunicación y Cultura de la Licenciatura en Gestión Cultural y Docente Auxiliar en la asignatura de Semiótica de la Licenciatira en Artes Combinadas y la Tecnicatira en Diseño de Imagen, Sonido y Multimedia de la Facultad de Artes, Diseño y Ciencias de la Cultura (FADyCC) de la Uiversidad Nacional del Nordeste. Fue docente Auxiliar en la cátedra "Herramientas de comunicación” de la Tecnicatura Universitaria de Guardaparques, Facultad de Ciencias Exactas, Naturales y Agrimensura, Universidad Nacional del Nordeste. Se ha desempeñado como tutor docente de cursillos de ingresantes, fue adscripto a la cátedra Formulación de Políticas de Comunicación de la Lic. en Comunicación Social, Facultad de Humanidades de la UNNE. 


\section{Introducción}

Las representaciones familiares en el cine y la televisión argentina poseen amplia tradición en la construcción de matrices que organizan un tipo de lógica binaria, nuclear ${ }^{1}$ y heterosexual como categorías universales, coherentes, naturales y estables que funcionan como patrones de prácticas y sentidos sexuales, relaciones afectivas y modos de ser y estar en el mundo (Moreno, 2008). Esta lógica deja por fuera del espectro representacional a otras posibilidades de conformación familiar, tales como las parentalidades lesbianas y gays de las cuales se ocupa el trabajo. Las mismas, irrumpieron en el espacio público demandando visibilidad y reconocimiento legal durante el debate por la aprobación la Ley de Matrimonio Igualitario $^{2}$ - en adelante LMI - e instalaron en la agenda la necesidad de acceso a los mismos derechos sin distinción de orientación sexo-afectiva.

Durante dicho debate, uno de los principales argumentos opositores estuvo basado en instalar sospechas acerca de qué sucedería cuando las parejas formadas por personas del mismo sexo, pudieran adoptar y tener hijos. Esta situación no se trataba de «un problema a futuro sino que constituyen hoy un hecho social. [...] la demanda de igualdad implica que estos nenes y nenas que ya existen tengan los mismos derechos que el resto de los niños y niñas del país» (Figari, 2010: 135). Estas otras familias, ya existían - y existen - pero se mantuvieron invisibilizadas por la matriz heterosexual ${ }^{3}$ que administra la inteligibilidad (Butler, 2007).

Este contexto de profundos cambios amparados en leyes, estuvo acompañado por la implementación de una serie de políticas públicas para el fomento de contenidos audiovisuales focalizados en la manifestación de la diversidad cultural argentina. Los subsidios y programas de financiamiento federales de producciones del Instituto Nacional de Cine y Artes Audiovisuales (INCAA) buscaron incentivar la producción de narrativas locales (Cáceres y Cáceres, 2012). Al mismo tiempo, la aprobación de la nueva Ley Servicios de Comunicación Audiovisual ${ }^{4}$ de 2009 emergió como

\footnotetext{
1 En términos de Jelin (2004) el concepto de familia nuclear, parte de un sustrato biológico que suele ligar la sexualidad, la procreación y la convivencia a una unidad fundada a partir del matrimonio monogámico. Su raigambre social está fundamentada en un proceso de naturalización que identifica a un tipo de familia particular como natural, que convive bajo un mismo techo, junto a sus hijos e hijas y un proceso de normalización que hace que dicho modelo de familia adquiera la nominación de normal frente a otros tipos que son considerados desviados.

2 Argentina fue el primer país de América Latina en reconocer el derecho de matrimonio entre personas del mismo sexo. El proyecto de ley modificatorio del Código Civil fue aprobado en la Cámara de Diputados el 5 de mayo de 2010 por 126 votos a favor frente a 110 en contra y cuatro abstenciones. En la Cámara de Senadores, la ley fue aprobada el 15 de julio de 2010 con 33 votos a favor, 27 en contra y 3 abstenciones.

3 Butler (2007) define como Matriz Heterosexual a la rejilla de inteligibilidad través de la cual se naturalizan cuerpos, géneros y deseos y donde la inteligibilidad de género da por sentado que para que los cuerpos sean coherentes y tengan sentido debe haber un sexo estable expresado mediante un género estable que se define históricamente y por oposición mediante la práctica obligatoria de la heterosexualidad.

4 Propone una nueva concepción de la comunicación en Argentina y contempla a las audiencias de radio y televisión como sujetos de derechos entendiendo que una de las principales demandas de la ciudadanía está vinculada a condenar la cosificación de las mujeres y la estigmatización de los colectivos de la diversidad sexual e identidad de género en los medios. En el 2016, la Cámara de Diputados aprobó el decreto de necesidad y urgencia 267/2015 que el ex Presidente
} 
otro episodio legislativo clave que excedió el marco de la norma para polemizar posiciones y acciones concretas en el campo de una reconfiguración del sistema de comunicación audiovisual (Gómez, 2012).

La producción documental argentina retrató por primera vez en un largometraje a cinco familias homoparetales en la producción Familias por Igual (2012) de Rodolfo Moro y Marcos Duzsczak, quienes buscaron «desmitificar el tema de la homosexualidad, mostrar que cada persona tiene su estilo de vida, que hay familias de dos papás y dos mamás que son como cualquiera y que crían a los hijos de forma normal» (Escribiendo Cine, 2012). Previo a su estreno, las series documentales Salida de Emergencia (2011) de Mathieu Orcel y Caleidoscopio: Diversos Colores, Los Mismos Derechos (2011) de María Victoria Glazmann comenzaron expandir la misma temática.

Estas producciones emergen en un contexto de demandas sociales de reconocimiento de la población LGBTIQ $+^{5}$ de sus vínculos y sus familias, en el marco de las cuales la visibilidad es entendida en términos de las posibilidades que existen para postular cuestiones susceptibles de discusión política, experiencias relacionadas con la intimidad, el cuerpo, el género y la sexualidad (Pecheny, Figari y Jones, 2008).

El primer apartado de este trabajo se denomina El documental como dispositivo generador de sentido y repasa las premisas teórico-metodológicas que guiaron el análisis. El segundo, se denomina El corpus: las series y los capítulos y profundiza en las características las producciones a partir de la toma de la palabra. Desde el tercero en adelante, se abordan cada una de las historias de vida y se retoman fragmentos representativos de los testimonios para titular cada apartado.

\section{El documental como dispositivo generador de sentido}

Para Bill Nichols (2013: 15) «La tradición documental depende en gran medida de nuestra capacidad para transmitir una impresión de autenticidad». A partir de esta premisa, los documentales son considerados como dispositivos que articulan entre dos instancias, aquella que corresponde a la puesta en obra de técnicas de producción sígnica y de procesos que hacen posible la circulación discursiva generando sentido (Traversa 2001; 2009).

La producción de sentido, colabora en la formación de representaciones que, tal como lo advierte Teresa de Lauretis (1989 [1996]) se consolidan a través de varias tecnologías del género, como el cine y de discursos institucionales, como teorías,

\footnotetext{
Mauricio Macri firmó al principio de su mandato para crear el Ente Nacional de Comunicaciones (ENACOM) y disolver a la AFSCA (Autoridad Federal de Servicios de Comunicación Audiovisual) y la AFTIC (Autoridad Federal de Tecnologías de la Información y las Comunicaciones). La resolución, además, estableció la creación de una "Comisión para la Elaboración del Proyecto de Ley de Reforma, Actualización y Unificación” de la Ley de Medios y de Argentina Digital.

5 La sigla LGBTIQ+ hace referencia a lesbianas, gays, bisexuales y trans, como una categoría inclusiva que refiere a transexuales, travestis y transgéneros, la I hace referencia a personas intersex, la Q a queer, y el + como posibilidad de ampliar las esferas identitarias a otras posibilidades no nombradas.
} 
que detentan el poder para controlar el campo de significación social y producen, promueven e «implantan» representaciones heterosexualizadas como únicos marcos válidos de comprensión y legitimidad social y cultural. La autora no descarta la posibilidad de que en los márgenes de los discursos hegemónicos subsistan prácticas micropolíticas que, fuera del contrato social heterosexual, tomen parte en la construcción del género en el nivel local de las resistencias, en la subjetividad y en la auto-representación.

La hipótesis que guía este trabajo considera que las producciones que forman parte del corpus son generadoras de representaciones sociales, que permiten poner en tensión la universalización del modelo de familia nuclear que fue sedimentado por la tradición audiovisual argentina y diversifica las formaciones familiares incluyendo a las paternidades lesbianas y gays dentro del espectro de posibilidades. De acuerdo con Arancibia (2015) las representaciones sociales son mecanismos traductores entre las prácticas y los discursos, poseen una facilidad notable para archivar y hacer circular con fluidez conceptos complejos cuya acentuación remite a sistemas de valores y modelos de naturaleza ideológica.

La articulación que se genera entre la noción de representaciones sociales y la de identidad, habilita la posibilidad de considerar la construcción identitaria como diversa y posicional en situaciones coyunturales concretas. La misma se rastrea en una multiplicidad de discursos y representaciones inherentes a un estado societario donde las identidades se construyen dentro de la representación y no fuera de ella (Hall, 1996).

En cuanto a la metodología y para trabajar la hipótesis, el trabajo utiliza el método cualitativo en lo que se refiere al análisis de los textos documentales anclados en las representaciones de las y los protagonistas. Por otra parte recurre al estudio contrastivo (Caggiano, 2012) que permite dar cuenta de las reconfiguraciones representacionales; es decir, observar qué imágenes, figuras y modos de narrar se reproducen y cuáles plantean la emergencia de repertorios alternativos.

Además se retoman los postulados del análisis textual (González Requena, 1980 y 1982; Aumont et al., 2008) a partir del cual hacer referencia al texto fílmico es considerarlo como discurso significante, analizar sus sistemas internos y todas las configuraciones que se puedan observar. Desde esta perspectiva el texto no se constituye de forma aislada sino que está antecedido y enmarcado por otros textos que los atraviesan (González Requena, 1980). En este último sentido resulta importante insertar entonces una actualización ideológica que funcionará como contexto en que se da el análisis de las series del corpus.

Para los procedimientos propios de análisis metodológico se retoman los postulados de la semiótica del cine de Christian Metz (1972) sobre los planos del contenido y la expresión. El autor propone un esquema comprendido por cuatro ejes: la materia del contenido que hace referencia al tema, la forma del contenido donde se ubica 
el punto de vista ideológico, la materia de la expresión que recupera los caracteres del soporte fílmico como imágenes en movimiento, signos escritos, voces, ruidos y música; y la forma de la expresión donde se identifican y analizan los recursos y procedimientos cinematográficos. Además resulta de utilidad la propuesta de Francesco Casetti y Federico di Chio (1991) a partir de la cual el acto analítico de las producciones audiovisuales consiste en operaciones de descomposición y recomposición que avanzan hacia la inteligibilidad del texto.

El análisis propuesto recupera fragmentos de los testimonios de los y las protagonistas de cada capítulo considerando que su puesta en circulación en las producciones les permite adquirir carácter público y dirigirse de manera explícita a una audiencia que varía en función del tipo de práctica social en la que se encuentran insertas (Aprea, 2012). Además tal como lo advierte Aprea (2010) la potencia del lenguaje documental audiovisual radica en la posibilidad del registro, no solo de lo dicho sino también de los elementos paratextuales que en muchos casos generan un efecto de transmisión de la experiencia vivida mucho más fuerte que la que puede dar una locución organizada.

En el marco de esta selección metodológica, el objetivo de este trabajo consiste en indagar acerca de las paternidades lesbianas y gays representadas en las producciones audiovisuales que forman parte del corpus. Estos materiales tienen en común el hecho de otorgar visibilidad a otras subjetividades y conformaciones familiares en Argentina desde los márgenes de los discursos hegemónicos y del contrato social heterosexual como su principal administrador. La puesta en pantalla de la diversidad familiar toma parte en la construcción del género y se constituye como un espacio que habilita la circulación testimonial, genera procesos de auto-representación y permiten tensionar la hipotética inexistencia de otros modelos familiares.

\section{EI corpus: las series y los capítulos}

Las condiciones de producción y reconocimiento (Verón, 1993) de las series documentales que conforman el corpus sugieren marcos interpretativos que permiten articular los discursos en un contexto más amplio donde la polifonía ofrece una alternativa que actualiza los horizontes de sentido y las representaciones en torno a temáticas que interpelan a diversos colectivos. Si bien el interés está puesto en la referencia a la diversidad familiar, su inscripción en procesos de transformación más amplios, aporta las bases para otro régimen de signos visuales que se alejan de la tradición audiovisual centrada en el modelo nuclear de familia y otorga visibilidad a la diversidad sexo-generica-identitaria en articulación con procesos de parentalidad.

Tal como lo advierte Mitchell (2014) las imágenes se inscriben en el campo social, abonando con escenas las múltiples posibilidades de mirar a otra/os y de ser mirada/os, ubicando a estas producciones como componente activos de la realidad social. Esas formas de inteligibilidad de otras familias se configuraron como criterio 
de selección de la muestra para que pueda dar cuenta de la amplia posibilidad de conformaciones familiares en Argentina como mitigación de la tradición audiovisual y su efecto de invisibilidad.

Salida de Emergencia (2011) de Mathieu Orcel ${ }^{6}$, consta de ocho capítulos que rondan los 25 minutos cada uno, tuvo pantalla en diversos espacios nacionales e internacionales y aborda una amplia variedad de tópicos. La serie dedica un capítulo específico al eje temático de este trabajo denominado Familias diversas, el cual propone un espacio de visibilidad para construcciones familiares no hegemónicas en las historias de Valeria y Daniela, una pareja de madres de Córdoba y de Sergio y Carlos, quienes conforman una familia ensamblada en San Miguel de Tucumán. El capítulo titulado Matrimonio Igualitario repasa la unión de Norma y Cachita de Buenos Aires y el vínculo que poseen con su hijo. Diversidad en el barrio se propone como tópico la relación de María y Stella de Rosario y los hijos que ambas comparten en su núcleo familiar.

Caleidoscopio: Diversos Colores, Los Mismos Derechos (2011) de María Victoria Glazmann $^{7}$, consta de cuatro capítulos de 25 minutos cada uno y es descrita en su sinopsis como una serie documental sobre:

«Cinco historias de vida que buscan derribar mitos y prejuicios sociales, sobre las elecciones diferentes a la heterosexualidad. La lucha de diversas personas por los mismos derechos, y la aprobación de la LMI y de Identidad de Género, fueron el punto clave para generar un cambio social».

La serie posee un capítulo denominado La maternidad que dedica la segunda mitad a la historia de Gela Alessio, quién gestó a su hijo por inseminación artificial ${ }^{8}$. La narración no profundiza en el método de reproducción asistida elegido sino que da cuenta de las diferentes formas en las que la decisión y el proceso fueron recibidos en su entorno.

\section{4. «Vivimos como cualquier ser humano y con todos los derechos»}

Valeria y Daniela se conocieron en el Mercado del Abasto nueve años antes del registro del documental y son dueñas de una carnicería. En su relato se advierten las transformaciones que tuvieron lugar en el país y que fueron modificando sus

\footnotetext{
6 La serie, fue galardonada con el Premio AFSCA, "Construyendo Ciudadanía”, participó del 18 Festival Chéries/ Chéris en Paris, del Festival de Montréal, Image \& Nation en Canadá, en el OUTVIEW Atenas Gay film Festival de Grecia, en la V Jornada contra la homofobia, Cenesex, Cuba, formó parte de la Selección Oficial del Regards d'Ailleurs, Dreux, Francia, del FICIP Festival de cine político, Argentina, fue ganadora de la Competencia Argentina del Festival Libercine, Argentina con un premio a Mejor Director de largometraje para Mathieu Orcel. Además se proyectó en diferentes pantallas nacionales e internacionales y se encuentra disponible en el canal de youtube de la productora (Konsud TV, 2014), .

7 Participó del Festival Internacional de Cine Social 2011 en Concordia, del $3^{\circ}$ Festival Internacional de Cine Político 2013 en Buenos Aires entre otros y fue puesta en pantalla en diversos espacios académicos y militantes.

8 También incluye la historia de Cristina y su hija Gabriela pero por motivos de extensión, no será incluido en el trabajo.
} 
concepciones acerca de las posibilidades de construcción de vínculos familiares reconocidos por la ley. Asimismo hacen mención a la inseminación como alternativa para la procreación en parejas de mujeres sin la necesidad de la intervención activa de un hombre.

\begin{abstract}
«Daniela: Diez años antes, yo decía, yo elijo ser homosexual y descarto la idea de casarme o de tener hijos como cualquier persona y diez años después digo, como cambio, como evolucionó todo, porque estamos casadas, porque tenemos un hijo, porque formamos una familia porque vivimos como cualquier ser humano y con todos los derechos como nos corresponde.

Valeria: Para nosotras fue un milagro, poder tener a nuestra hija, yo llevarla en la panza sin tener que haber estado con un hombre, un sueño cumplido» (Salida de emergencia, Cap. 02, Min: 01:59).
\end{abstract}

En las secuencias que muestran a Valeria y Daniela se puede advertir al menos tres espacios narrativos diferentes en la carnicería en la que trabajan: el patio, una oficina y el mostrador de atención al público. El primero es el lugar primordial de toma de la palabra, Daniela se encuentra sentada a la izquierda con el delantal que utilizan para trabajar y Valeria a su derecha con su hija en brazos. Durante la entrevista se van intercalando primeros planos que ponen el foco en quien va llevando el relato o en su bebe. El montaje permite mostrarlas mientras trabajan y por medio de la voz en off continuar con el desarrollo de su historia que, en la dimensión sonora, no solo registra sus voces sino también los sollozos de su hija que se encuentra por momentos dentro y fuera de la toma.

En la oficina Daniela muestra a la cámara imágenes de su ceremonia y fiesta de casamiento, mientras comenta anécdotas acerca de esa fecha: «Fue un casamiento soñado, como el de cualquier persona. Que estuviera, por ejemplo, mi abuelo de 89 años era... cero problemas. Al contrario, todos re emocionados y felices» (Salida de emergencia, Cap. 02, Min: 10:36). Esta anécdota es acompañada por el sonido ambiente generado por los golpes y la cierra de cortar en la carnicería, paliando la neutralidad del lugar y anclando el espacio de la enunciación.

La escena que transcurre en el mostrador de atención al cliente muestra a las protagonistas y clientes/as del negocio. En esta secuencia Daniela expresa: «Esto es nuestra vida, es todo para nosotras esto, o sea, de acá laburamos, de acá vivimos» y esto se completa con algo que agrega Valeria: «todo para una mejor calidad de vida para Angie, uno piensa todo en eso, como verás la gorda también está acá» (Salida de emergencia, Cap. 02, Min: 14:29).

En la construcción de la representación de la experiencia familiar de Daniela y Valeria, también toma la palabra su abogado Carlos de Falco, quien se refiere a la situación legal de Angie y al ejercicio de la maternidad ocupando el rol de testigo. De Falco destaca una serie de prácticas constitutivas de repertorios de sexo/género que son reconocibles como guiones o pautas culturales de actuación (Butler 2005; Scott, 2000). 
En este caso reconoce su estatus de madres a partir de la constatación que hace de los cuidados que brindan a su hija, pero no sin dejar en claro que su experiencia no es la de un psicólogo. Esta aclaración hace emerger al discurso médico como legitimador de experiencias de vida y la persistencia de concepciones que consolidan los mitos en torno al género y los roles que ocupan varones y mujeres en la crianza. De acuerdo con Fernández (2006: 162) esos mitos aluden a la «producción y reproducción de un universo de significaciones imaginarias constitutivas de lo femenino y lo masculino moderno que forman parte no sólo de los valores de la sociedad sino también de la subjetividad de hombres y mujeres».

Los testimonios de Valeria y Daniela insisten en la categoría de la normalidad que, en sus términos, está dada por la iteración de una serie de prácticas que constituyen las formas de habitar y significar a la familia. La fuente de la subversión para Butler (2007) se encuentra dentro de la cultura y por ende, las posibilidades de trasformación social deben ser realizadas con recursos y formas de acción propias del sistema, imitando actos previos pero alterando su sentido. La alteración, en este caso, parte de la reproducción de ciertas prácticas culturales de la configuración hegemónica de familia nuclear pero con la presencia de dos madres donde su inexistencia es paliada con la puesta en pantalla como prueba de vida, de humanidad y de fertilidad.

Figura 1. Valeria y Daniela con su hija Angie en el capítulo Familias Diversas

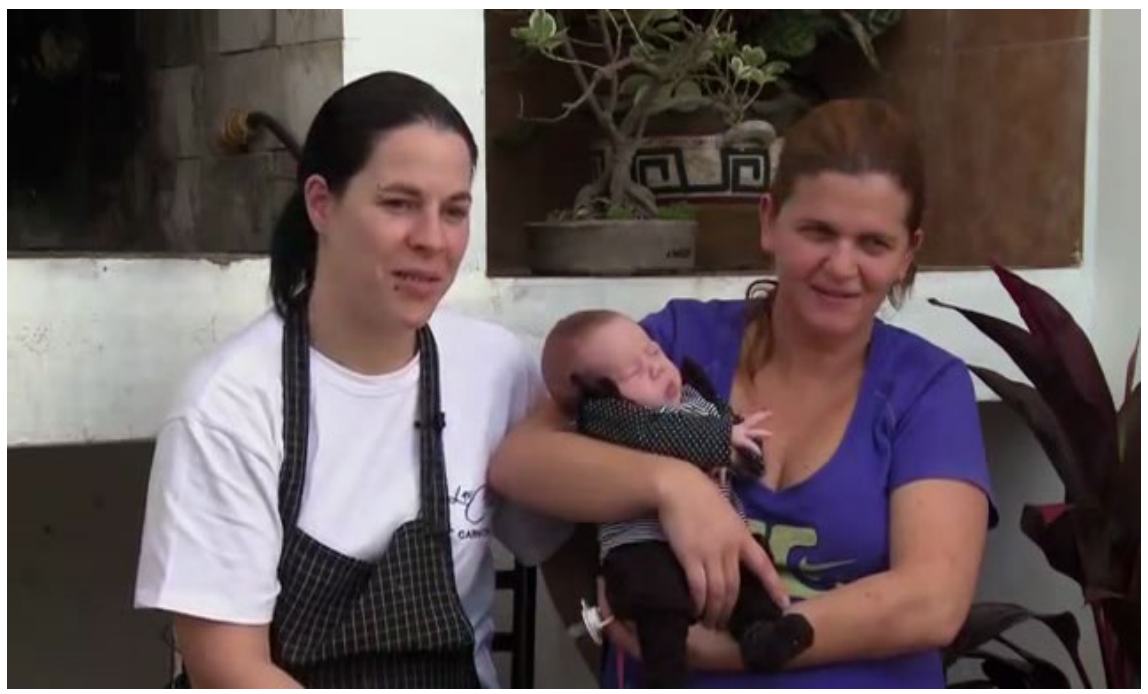

Fuente: Salida de emergencia, Cap. 02, Min: 01:19. 


\section{5. «Para mí es el hijo del corazón»}

Sergio y Carlos viven en San Miguel de Tucumán y su entrevista tiene como punto de inicio imágenes de archivo de los protagonistas militando por la aprobación de la LMI. Luego de una transición se los muestra en un plano americano observando la pantalla de una computadora de escritorio que retoma el final del video que acaba de mostrarse. Sergio comienza su relato hablando a la cámara: «En esta foto ustedes podrán verlo a Fabio, al amor de mi vida. Este fue un día muy significativo, muy memorioso, porque es el día que vamos a pedir el turno para casarnos» (Salida de emergencia, Cap. 02, Min.: 05:22).

El escenario en el que transcurre la mayor parte del registro documental es la cocina-comedor de su casa. Allí, el relato de Sergio comienza con las circunstancias del fallecimiento de Fabio, lo que se contrapone con una situación festiva obtenida de imágenes de archivo en la que se los ve entre aplausos y flashes fotográficos contrayendo matrimonio, siendo entrevistados y saliendo del Registro Civil bajo una lluvia de arroz al grito de «igualdad, igualdad, igualdad» (Salida de emergencia, Cap. 02, Min.: 06:52).

Luego se muestra a Gustavo relatando acerca de la llegada de Carlitos a la vida de la pareja y toma la palabra su tía Cristina, hermana de Fabio. Estos fragmentos testimoniales constituyen repertorios alternativos que resignifican la noción de familia en tensión con el modelo nuclear heterosexualizado:

\footnotetext{
Gustavo: «Fabio se contacta con su mamá y su mamá le dice que no lo podía atender, si él se podía hacer cargo. Y es ahí que Fabio y yo con una inmensa alegría, Fabio por haberse enterado de la noticia y yo que iba a tener a mi hijo, que para mí es el hijo del corazón. Hoy en la actualidad Carlos tiene once años y seguimos para adelante» (Salida de emergencia, Cap. 02, Min: 09:25).

Cristina: «Esta familia es para toda la comunidad, no solo acá de Tucumán sino de muchos lugares, son las familias nuevas, que no son de ahora, siempre existieron, ahora están a la luz, pero siempre estuvieron, son familias comunes y corrientes, criadas en base al amor. $\mathrm{Al}$ amor de un padre, al amor de otro padre, al amor de una madre, de otra madre, se complementa con tíos, con sobrinas, amigos, amiguitos de Carlos, todo se conversa, todo se debate en familia, todo se discute, se sonríe y se sigue para adelante $[\ldots]$ ahora nos queda pendiente luchar para que Sergio y Carlitos estén juntos como tiene que ser, porque Sergio es el papá de Carlitos» (Salida de emergencia, Cap. 02, Min: 15:53).
}

De las series analizadas, la historia de Gustavo y Carlos es la única que presenta un caso de paternidad de una pareja de varones. La complejidad está dada por la condición legal de su vínculo ya que al momento del fallecimiento de Fabio - el padre biológico - aún no habían realizado los trámites de adopción. En los testimonios de Gustavo y de Cristina se hace referencia a una idea de familia ampliada en la que existe una comunidad de participa activamente en la crianza y los cuidados del niño. Tal como lo advierte Micaela Libson (2012) al igual que las nociones sobre maternidad, los conceptos de paternidad suponen una construcción (Lupton 
y Barclay, 1997 en Libson, 2012) que instala y arraiga determinadas experiencias en un contexto social, político, económico y cultural específico que remite a «un campo de prácticas y significaciones culturales en torno a la reproducción, al vínculo que se establece o no con la progenie y al cuidado de los hijos» (Fuller, 2000: 36 en Libson, 2012).

El capítulo muestra un padre que compartía el cuidado de su hijo con su compañero fallecido recientemente y que frente a esta situación, debe apelar a la justicia para permanecer a su lado. El vínculo puesto en pantalla no responde a requisitos biológicos relacionados con la procreación sino que testimonia la preexistencia de otros modelos familiares que como en este caso dan cuenta de otra forma de organización posible en contraste con el modelo nuclear heterosexual.

Figura 2. Sergio y Carlitos en el capítulo Familias Diversas

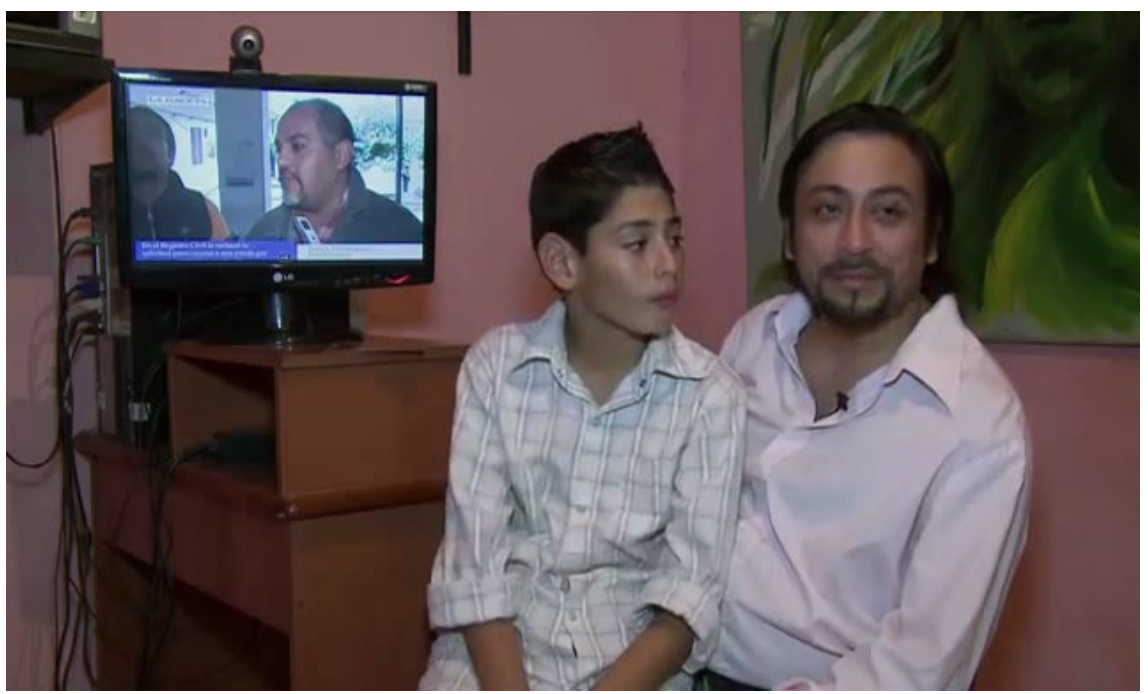

Fuente: Salida de emergencia, Cap. 02. Min: 06:01.

\section{6. «Tenemos 31 años ya de estar hablando»}

El capítulo Matrimonio Igualitario presenta la historia de Norma, oriunda de Corrientes Argentina, y Cachita ${ }^{9}$, de Montevideo Uruguay, una pareja de mujeres que

9 El pasado 26 de octubre de 2018, a sus 75 años Cachita falleció. La noticia se hizo eco en medios de todo el país ya que junto a Norma, formaron la primera pareja de mujeres de Latinoamérica en casarse siendo uno de los nueve matrimonios que se concretaron antes de la sanción de la Ley de Matrimonio Igualitario por fallos judiciales y representaron un antecedente clave para la aprobación de la Ley, además su aporte fue fundamental para visibilizar el afecto de lesbianas adultas mayores. 
vive en Buenos Aires y que al momento del registro de capítulo contaban con más de 31 años de relación. Los espacios narrativos están dados por el recorrido que se van haciendo de su casa.

Desde la puerta de acceso, la cámara acompaña cada uno de los testimonios intercalando planos generales, primeros planos y planos detalles de las situaciones que se van generando en cada etapa de la entrevista. Cobran relevancia, las tomas dónde la cámara recupera sus rostros y sus manos que denotan su edad avanzada, las fotografías que testimonian su niñez, infancia, viajes y su matrimonio.

El eje argumental de la entrevista está dado por su matrimonio y las vivencias conjuntas a lo largo de los años, donde el acto de recordación como rescate del pasado abona con diversos componentes una vida resistente a la falta de reconocimiento legal. El desamparo de la ley culmina y encuentra en la aprobación de la LMI una celebración de lo acontecido, del pasado que pervive en el presente, en la continuidad de su unión y las formas en las que lidiaron con el entorno:

«La reafirmación de algo que es real internamente, que es que nos queremos una barbaridad. Que todavía después de treinta años lo que buscamos antes de dormir es un abrazo y un beso y sentir que eso es maravilloso. Y que te den un documento diciendo, esa vida tuya vale como ser humano» (Salida de emergencia, Cap. 01, Min: 01:31).

El fin del desamparo legal del vínculo es considerado en este contexto como el reconocimiento de la condición humana a partir del acceso a los mismos derechos que poseen las parejas heterosexuales en un país donde esta posibilidad mantuvo al margen a aquellas conformadas por personas del mismo sexo. La política del reconocimiento y de la igual dignidad, demanda la universalización de todos los derechos y un trato para todas las personas, basado en el estatus compartido de humanidad o ciudadanía, en caso de que esos derechos no sean universales se genera la existencia de ciudadanos de primera y segunda clase (Taylor, 2009 en Marshall, 2019). Esta diferencia genera un efecto que privilegia a cierto sector poblacional en desmedro de otro que encuentra limitaciones en el pleno desarrollo de sus posibilidades de existir.

El documental cumple la función de registrar este devenir igualitario al «elevar al campo de lo visible a los grupos sociales privados de voz pública» (Meccia, 2011: 29). Entre esos grupos se encuentran los/as adultos/as mayores, quienes vivieron sus procesos de aceptación sin exposición y en la actualidad, frente al reconocimiento, padecen un regreso a la vulnerabilidad de la exposición «cuando ya habían conseguido sobrevivir medianamente bien en la oscuridad» (García Albertos, 2018: 140).

El momento en el que hacen referencia a la maternidad de Cachita es breve y transcurre con ellas sentadas sobre un sofá acariciando a su mascota. La configuración de la familia se complementa con fotografías que acompañan la narración: 
«Tuve una pareja, quedé embarazada y tuve mi hijo y nos separamos, yo lo crié sola, con ella, cuando él ya se enteró de que nosotras éramos pareja, dijo que no tenía ningún problema que si yo era feliz, él también era feliz. El, la quiere mucho a ella, la eligió de madrina de matrimonio» (Salida de emergencia, Cap. 01, Min: 19:18).

En las fotografías se muestra a ambas acompañadas del núcleo familiar de su hijo en el día de su boda, como una postal modificada en la que la presencia del padre es ocupada por una mujer, actualizando de esta forma un repertorio alternativo en el álbum familiar. El sentido se ancla cuando Cachita explica que lo criaron juntas y que Norma es la madrina de su boda, eliminando así cualquier tipo de confusión que pueda generar la presencia de dos mujeres en el cuadro. Se apela en esta mostración a la eliminación de la ambigüedad fotográfica que advierte Boris Kossoy (2000) al afirmar que el potencial informativo de las fotografías puede ser alcanzado en la medida que sean contextualizadas en la trama histórica en sus múltiples desdoblamientos.

Las formas de representación de Norma y Cachita testimonian la permanencia y la resistencia a la invisibilidad y falta de reconocimiento. En este sentido el discurso documental hace uso de sus potencialidades para poner en pantalla y otorgar visibilidad a la población conformada por adultos/as mayores y las alternativas de conformaciones familiares existentes que desde el margen tensionan la institucionalidad heteronormativa en tanto, coherente, natural y estable como organizadora de prácticas y sentidos sexuales, relaciones afectivas y modos de ser y estar en el mundo.

Figura 3. Norma y Cachita en el capítulo Matrimonio Igualitario

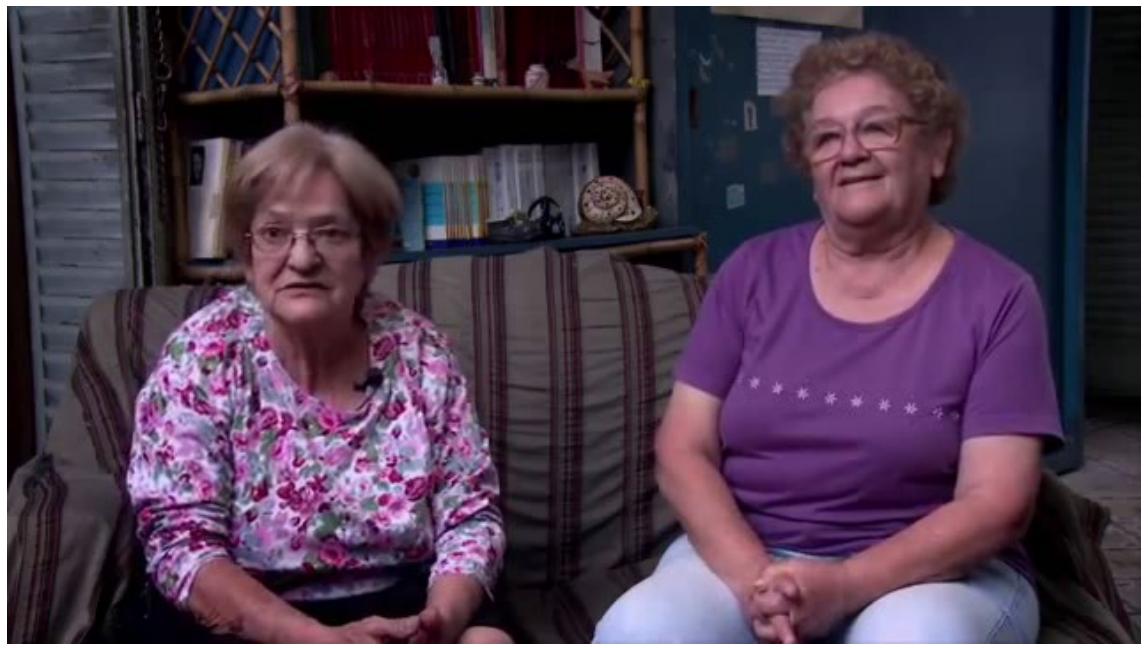

Fuente: Salida de Emergencia, Cap. 01, Min: 21:41. 


\section{7. «Ustedes son lesbianas les vamos a sacar el nene»}

El testimonio de María y Estela inicia con una toma que enfoca la pantalla de su teléfono celular donde se encuentra observando una fotografía de su casamiento. El tópico sobre el cual gira esta primera secuencia está centrado en el deseo manifiesto de poder casarse y de la imposibilidad que esto representaba antes de la sanción de la LMI en Argentina:

María: «Pero lo más divertido de todo esto es que a los tres meses de conocerla a ella le dije si se quería casar, y me dice, no, vos estás loca... Vos acordate que vos vas a llevar mi apellido y ahí está, me casé, yo llevo el apellido de ella y ella el mío» (Salida de Emergencia, Cap. 05, Min: 01:10)

El espacio narrativo privilegiado para su testimonio es el patio de su casa, la cámara las muestra sentadas en unas sillas mientras toman mate con una parrilla de fondo, maderas y chatarra apilada debajo de un toldo que las cubre del sol. En otros momentos del capítulo recorren el barrio, por calles de tierra, mientras circulan a su alrededor personas en bicicletas, perros, caballos, carros de cirujeo $^{10}$. Las formas de representación instalan un tópico poco abordado que se refiere al vínculo entre la diversidad sexo-genérico-identitaria, la pobreza y las consecuencias que acarrea la construcción identitaria fuera del closet en los márgenes de los centros urbanos. En sus palabras se identifican los modos de narrar tradicionales de la representación mediática que insiste en un determinado perfil que el mercado estableció como segmento de consumo y que contrasta, invisibiliza y excluye a personas ubicadas en posiciones económicas desfavorables.

María: «Me da bronca, que se nos catalogue que siendo gay, lesbiana, transexual, tenemos plata y no es así. Hay un mundo, que es boliche, auto, vacaciones, cruceros, no, nosotros vivimos una realidad diferente, distinta y no es como mucha gente piensa» (Salida de Emergencia, Cap. 05, Min: 03:30)

El marco de posibilidades que hablita el reconocimiento legal de su vínculo, también dialoga con las formas a partir de las cuales se van construyendo códigos en el barrio para lograr que las respeten. La idea de «barrio» funciona, no solo como el espacio geográfico de Rosario donde viven con su familia y poseen un comedor comunitario, sino también como un régimen de administración de las formas relacionales que se consideran tolerables en el espacio público. Si bien se las reconoce como una familia, al mismo tiempo, existen ciertos comportamientos que se encuentran vedados por decisión personal como resultado de la presión del entorno.

María: «Nos costó que nos respeten, porque nos han insultado, nos han dicho un montón de cosas [...] estamos casadas, pero de tocarnos, de besarnos y que ellos nos vean, eso es nuestro código, no. Acá dentro del barrio, es eso» (Salida de Emergencia, Cap. 05, Min: 09:17).

10 El término ciruja, que proviene del lunfardo, hace referencia en este contexto a personas que trabajando de la recolección de objetos que luego pueda utilizar, consumir o vender. 
«Para el barrio ya somos una familia constituida, para nosotros lo que cambia es — por la LMI - que se reconozca nuestro derecho. Que el día que yo falte o que ella falte, ella pueda heredar lo mío, como mi hijo, mis hijos. El hijo de ella y mío. A Brian lo empezamos a criar juntas desde los tres años. Fuimos amenazadas muchas veces, ustedes son lesbianas les vamos a sacar el nene, vamos a ir a la justicia. Vayan, les decía yo, los espero con los brazos abiertos, vayan. Y cuando yo me casé, le dije ahora, nos casamos y bueno, que ahora vengan a sacarte tu hijo, yo estoy casada legalmente con vos» (Salida de Emergencia, Cap. 05, Min: 16:19).

El recorrido por los escenarios y los testimonios vehiculizados en el capítulo tienen como objetivo agregar otro elemento que condiciona las formas de pensar la diversidad sexo-generico-identitaria, relacionada a la dimensión socioeconómica en la que se insertan las protagonistas. Lo cual opera como una forma de diversificar y completar espacios de vacancia en relación a la representación de la población LGBTIQ+ y sobre las familias que construyen identidad en y desde sus contextos. El matrimonio además es valorado como una garantía de defensa frente a la vulnerabilidad en la que se encontraban las familias constituidas al margen del contrato heterosexual.

Figura 4. María y Estela en el capítulo Diversidad en el Barrio

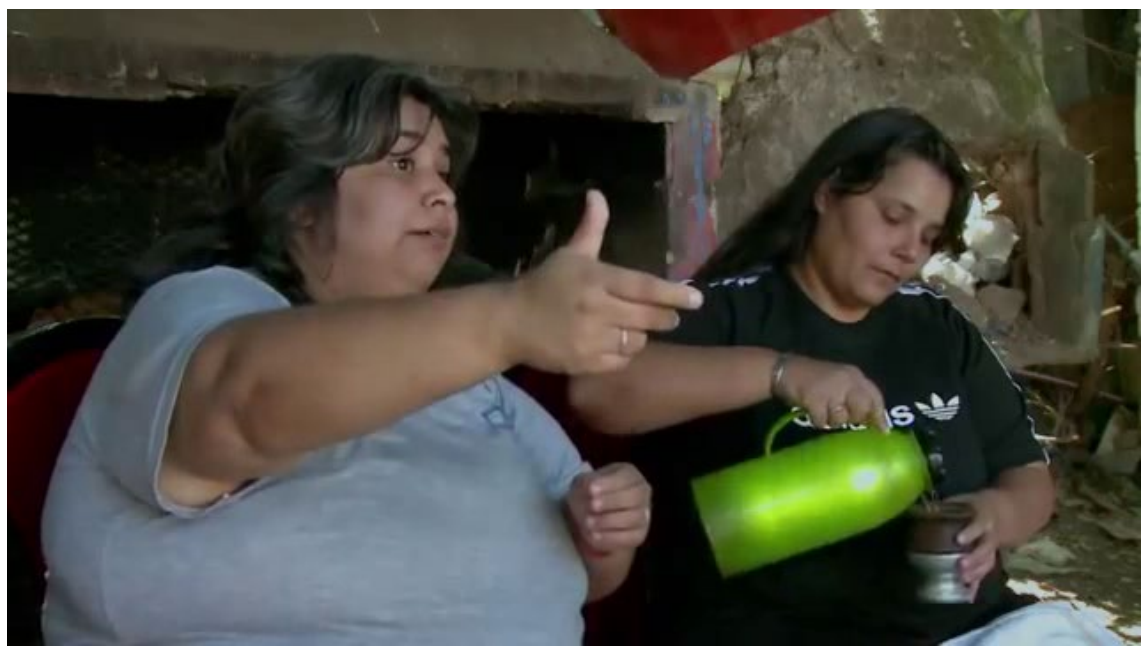

Fuente: Salida de Emergencia, Cap. 05, Min: 08:57.

\section{8. «No se imaginaba que era un bebé de enserio»}

En la segunda mitad del capítulo La maternidad, de la serie documental Caleidoscopio..., se da inicio a la historia de Gela Alessio. La narración comienza mostrando su llegada a la institución en la que trabaja dando clases. El segundo espacio en la 
representación de la cotidianeidad está dado por la escena siguiente que se ubica en el interior de una casa donde mantiene una conversación con su hermano Mariano. Las tomas van intercalando sus rostros a medida que avanza el relato acerca de su proceso de inseminación artificial:

\begin{abstract}
Gela: «Una mañana llegué, me senté a tomar mate con ellos, y les dije, $[\ldots]$ che estoy embarazada fue medio como una mezcla entre estupor, sorpresa... y ¿qué es esto? Viste... [...] Ellos sabían que yo me hacía inseminación pero nunca entendieron, ni siquiera ahora creo que entienden. [...] después yo empecé a tener panza, mi embarazo era re visible y me acuerdo el día que nació el Santi en el hospital, que la Dani los llamó a los viejos para contarles. Y me acuerdo que el Santi nació a las siete de la tarde y mi vieja habrá llegado a las ocho y media, y entró a la pieza, yo estaba con el Santi dándole la teta y lo vio al Santi y se largó a llorar y le digo, ¿mamá por qué lloras? Y me dice, ¡es de verdad! Esta cosa donde hay un embarazo sin un hombre físico, no se imaginaba que era un bebé de enserio» (Caleidoscopio... Cap. 04, Min.: 15:47)
\end{abstract}

A diferencia de Salida de emergencia, donde los y las protagonistas hablan a la cámara, en Caledoscopio... el relato de Gela se va construyendo como un diálogo con su hermano. Este modo de narrar permite poner en pantalla la historia de una mujer lesbiana que optó por la inseminación artificial para convertirse en madre y las repercusiones que eso tuvo en su familia y específicamente en su madre quien no comprendía la posibilidad de que un niño o niña sea engendrado/a sin la intervención activa de un varón.

La persistencia de los marcos válidos de inteligibilidad construidos en base al contrato heterosexual, mantuvieron convenientemente invisibles otras posibilidades de concepción y gestación de niños y niñas al tiempo que también fueron construyendo mandatos que establecían - y en muchos lugares permanecen- condenas sociales a madres solteras o madres emparejadas con otra mujer. La puesta en pantalla de la historia de Gela visibiliza repertorios alternativos de conformación familiar al tiempo que avanza en la normalización de otras posibilidades de concepción de mujeres que poseen el deseo de ser madres.

En la escena siguiente se encuentra con dos amigas donde el dialogo que sostienen hace referencia al embarazo de una de ellas y la maternidad es el tópico en torno al cual se desarrolla la charla. Rememoran además, las transformaciones que se fueron dando en sus concepciones acerca de la maternidad, el rol del padre en la crianza de los niños y las formas de afrontar la falta de la figura paterna ante el mandato que modeliza la conformación de las familias nucleares en el marco del contrato heterosexual. Esto queda manifestado en lo que su amiga Bárbara Short expresa acerca del deseo de Gela de ser madre:

Bárbara: "Yo no entendía como un hijo podía nacer sin padre, por la estructura familiar a la que estamos acostumbrados, ahora como que tengo la cabeza en otro lado, con lo del Santi y otros niños que vinieron también en camino. [...] yo te cuestionaba que a mí me parecía que no estaba bueno que no tenga papá o qué le vas a decir cuando quiera conocer a su papá y ella siempre me hablaba del amor. El amor es algo que uno siente y al papá lo ves. Era algo 
que no me convencía en ese momento y no me convenció hasta que el Santi nació, siempre bueno, lo respeté obviamente» (Caleidoscopio... Cap. 04, Min: 20:36).

En lo expresado se ponen en común posturas opuestas acerca de las nociones de familia y del avance que implica considerar la existencia de otras parentalidades. Los argumentos que encuentran su basamento en el sentido común, instalaron que la presencia de la figura paterna y la materna, son condiciones indispensables para la procreación y crianza de los niños y niñas. Esta premisa fue sedimentada produciendo un doble efecto: por un lado legitimando construcciones familiares implantadas por las tecnologías de género basadas en el modelo nuclear y por el otro invisibilizando otras.

El censo realizado por el Instituto Nacional de Estadística y Censos en el año 2010 dio cuenta de que en el país habían 24.228 hogares compuestos por parejas del mismo sexo, 4.960 de ellos integrados por mujeres a cargo de hijos e hijas (Instituto Nacional contra la Discriminación, la Xenofobia y el Racismo - INADI-, s.f.). La persistencia de estas ideas expresadas en muchas de las experiencias registradas en las series documentales analizadas, dan cuenta de la eficacia de las representaciones del género desde la multiplicidad de instituciones que se encuentran a su servicio para priorizar una determinada configuración discursiva acerca de la familia.

La escena final del capítulo, muestra a Gela en su casa jugando con Santi en una competencia de rompecabezas. El registro está centrado, como en todos los capítulos de la serie, a representar una situación que ignore la presencia de la cámara.

Figura 5. Gela y Santi en el capítulo La maternidad

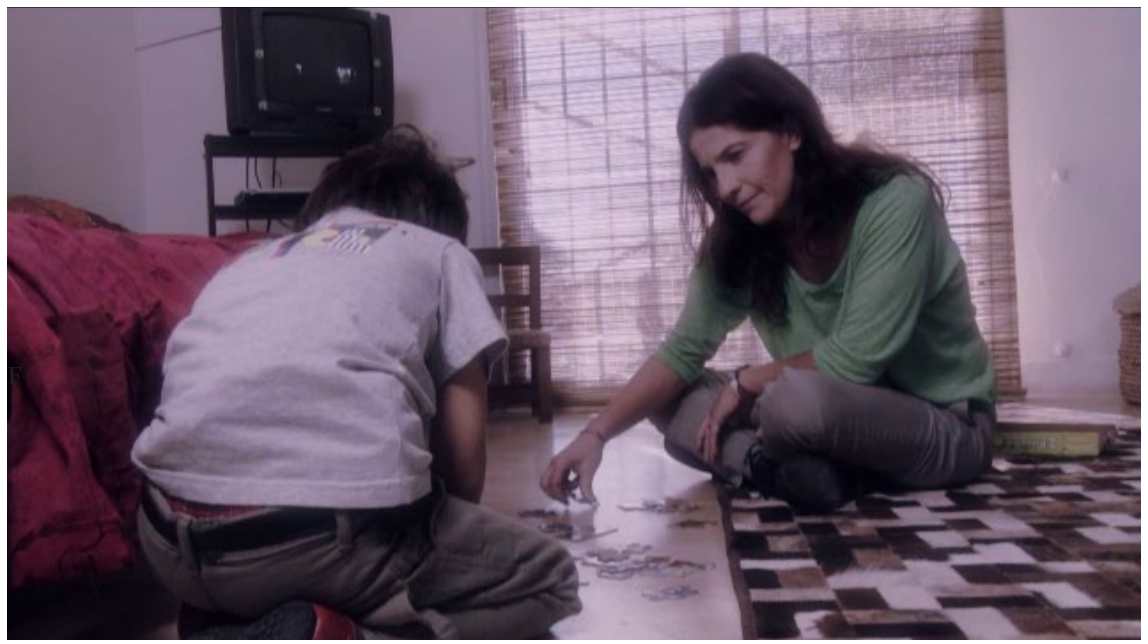

Fuente: Caleidosconio: Diversos colores, los mismos derechos, Cap. 04, Min: 24:54. 
La cercanía y la predominancia de los primeros planos posicionan al espectador como espía durante el juego entre una madre y su hijo en el interior de su casa. La imagen se encarga de responder a muchas preguntas planteadas en la escena anterior que sometían a juicio las formas en que se cría y crece un niño sin padre, como requisito necesario para su pleno desarrollo: esos niños y niñas se crían igual que el resto, con amor, jugando y aprendiendo.

\section{Conclusiones}

Este trabajo tomó como punto de partida la identificación del estado de invisibilidad mediática en la que se encontraban las formaciones familiares constituidas fuera del modelo nuclear y del contrato heterosexual. Durante los debates por la aprobación de la LMI emergieron demandas de identificación y reconocimiento de esas otras familias para lograr la universalización de derechos reservados a aquellas que habían sido construidas como «normales» por las tecnologías del género.

Este contexto también se vio caracterizado por políticas públicas de fomento para la producción audiovisual que buscaron mostrar la diversidad cultural del país posibilitando la producción de las series analizadas. Salida de Emergencia (2011) y Caleidoscopio: Diversos colores, los mismos derechos (2011) fueron producidas y habilitaron modos de narrar desde una lógica de resistencia frente a un estado de situación donde el discurso audiovisual se mantuvo - y se mantiene- predominantemente al servicio de la reproducción del contrato social heterosexual que instala y consolida formas específicas de lectura de la realidad.

El análisis constrastivo de los capítulos de las series permite identificar que la puesta en pantalla de otras experiencias familiares tensiona la proliferación hegemónica de la heterosexualidad institucionalizada que fue instalando una clasificación de ciudadanos y ciudadanas de segunda clase. Estas experiencias invisibilizadas, al acceder al estatus público, cumplen la función de diversificar el paisaje mediático y asumen un rol configurativo de la identidad como componentes activos de la realidad.

La historia de Valeria y Daniela advierte las transformaciones que tuvieron lugar en Argentina y que fueron modificando sus propias concepciones acerca de las posibilidades de construcción de vínculos familiares. La familia conformada por Gustavo y Carlos, pone en pantalla la paternidad de una pareja de varones y su continuidad cuando uno de ellos ya no se encuentra presente descartando al requisito procreacional en los vínculos filiales. Norma y Cachita se presentan como testimonio vivo de la permanencia y resistencia de los vínculos y otorga visibilidad a la población conformada por adultos/as mayores y las alternativas de conformaciones familiares existentes.

Esa diversidad sexo-genérica en el plano parental también se ve complejizado en los testimonios de María y Estela, en los que la dimensión socioeconómica opera como condicionante para completar espacios de vacancia en relación a la representación 
de la población LGBTIQ+ y sobre las formas en las que las familias construyen identidad en y desde sus contextos, donde el matrimonio es valorado como una garantía de defensa frente a la vulnerabilidad legal.

La historia de Gela y Santi, registra varios casos de negociación con los mandatos del sentido común construidos por las representaciones de género que implicaron comenzar a considerar la existencia de otros modelos familiares por fuera del modelo nuclear y la puesta en duda de la necesaria presencia conjunta de la figura paterna y materna como condiciones indispensables para la procreación y crianza de los niños y las niñas. Esta historia no profundiza en los métodos de reproducción asistida sino que apela a la puesta en pantalla de las concepciones del sentido común y el conflicto que generan las prácticas de ruptura con las representaciones tradicionalmente institucionalizadas.

Las y los protagonistas, a lo largo de cada capítulo, se apropian de las potencialidades del relato audiovisual para narrarse y de esta forma tensionar las posibilidades de lo que la matriz heterosexual delimita como «normal». La puesta en pantalla de sus historias pone en circulación una serie de repertorios alternativos acerca de la familia y permite desestabilizar representaciones consolidadas en torno a un modelo único frente al cual estas experiencias de vida reclaman reconocimiento.

Estas otras familias, exceden la tradición representacional devolviendo a la capacidad narrativa su rol configurativo de la identidad y de disrupción en el espacio público. Ese espacio, como escenario de circulación mediática, establece las condiciones para que lo inteligible amplíe su espectro y se torne testimonio.

\section{Referencias}

Aprea, Gustavo (Comp.) (2012). Los usos de los testimonios en los documentales audiovisuales argentinos que reconstruyen el pasado reciente. En: Aprea, Gustavo (Comp.) Filmar la memoria. Los documentales audiovisuales y la reconstrucción del pasado. Buenos Aires: UNGS.

Aprea, Gustavo (2010). Dos momentos en el uso de los testimonios en autores de documentales latinoamericanos. En: Cine Documental, $\mathrm{n}^{0} 1$. Buenos Aires: Cine Documental.

Arancibia, Víctor (2015). Nación y puja distributiva en el campo audiovisual. Identidades, memorias y representaciones sociales en la producción cinematográfica y televisiva del NOA (2003-2013). Tesis Doctoral. La Plata: Universidad Nacional de La Plata.

Butler, Judith (2005) Cuerpos que importan. Sobre los límites materiales y discursivos del "sexo". Buenos Aires: Paidós.

Butler, Judith (2007) El género en disputa. El feminismo y la subversión de la identidad. Barcelona: Paidós. 
Caggiano, Sergio (2012). El sentido común visual. Disputas en torno a género, "raza” y clase en imágenes de circulación pública. Buenos Aires: Ed. Miño Dávila. Cáceres, Carlos Esteban; Cáceres; María Alicia (2012). El cine ha muerto. ¡Larga vida al cine! El Plan de Fomento del INCAA ante el desarrollo de la tecnología HD. En: Toma Uno, $\mathrm{n}^{\circ} 1$. Córdoba: Universidad Nacional de Córdoba.

Casetti, Francesco; Di Chio, Federico (1991). Cómo analizar un film. Barcelona: Paidós.

De Lauretis, Teresa (1989). La tecnología del género. Consultado el 21 de enero de 2020 en: https://perio.unlp.edu.ar/catedras/system/files/teconologias-del-generoteresa-de-lauretis.pdf

Escribiendo Cine (2012). "Familias por Igual”: Un documental argentino sobre familias gay. Consultado el 21 de enero de 2020 en: http://www.escribiendocine.com/ noticia/0005252-familias-por-igual-un-documental-argentino-sobre-familias-gay/

Figari, Carlos (2010). Per scientiam ad justitiam! Matrimonio igualitario en Argentina. En: Mediações, vol.15, $\mathrm{n}^{\circ} 1$. Londrina: Editorial Universidade Estadual de Londrina, 125-145.

García Albertos, Marina (2018). Mayores y Diversidad sexual: Entre la visibilidad y el derecho a la indiferencia. En: Revista Prisma Social, $\mathrm{n}^{0} 21$. Madrid: Fundación iS+D para la Investigación Social Avanzada, 123-148.

Gómez, Lía (2012). Construyendo historias. Ver para creer en la Televisión. Relatos y narraciones en la Televisión Digital Argentina. La Plata: Ediciones EPC.

González Requena, Jesus (1980). Film, texto, semiótica. En: Contracampo, no ${ }^{0} 13$. Niterói,: PPGCOM/UFF, 51-61.

González Requena, Jesús (1982). La fractura de la significación en el texto moderno. En: Contracampo, $\mathrm{n}^{0}$ 28. Niterói: PPGCOM/UFF, 50-58.

Hall, Stuart (1996). Introduction: who needs identity? En: Hall, Stuart; Du Gay, Paul (Eds.). Questions of cultural identity. Londres: Sage Publications.

Instituto Nacional contra la Discriminación, la Xenofobia y el Racismo (INADI) (s.f.). Diversidad sexual y derechos humanos. Sexualidades libres de violencia y discriminación. Consultado el 21 de enero de 2020 en: http://www.inadi.gob.ar/ contenidos-digitales/wp-content/uploads/2017/06/Diversidad-Sexual-y-DerechosHumanos-9-9-2016.pdf

Jelin, Elizabeth (2004). Educación y memoria: la escuela el pasado. Madrid: Siglo XXI.

Konsud TV (2014). Salida de emergencia. Consultado el 21 de enero de 2020 en: https://www.youtube.com/watch?v=WCHcvCcSx-g\&list=PLx_y8iSTp-1yzkqtJGlzdZa_vianIXdKp 
Kossoy, Boris (2000). O relógio de Hiroshima : reflexões sobre os diálogos e silêncios das imagens. São Paulo: Red Revista Brasileira de História.

Libson, Micaela Cynthia (2012). Parentalidades Gays y Lesbianas: Varones y Mujeres en Familias No Heteronormativas. En: La Ventana: Revista de Estudios de Género, n³5. Guadalajara: Centro Universitario de Ciencias Sociales y Humanidades de la Universidad de Guadalajara, 292-321.

Marshall, Pablo (2018). Matrimonio entre personas del mismo sexo: una aproximación desde la política del reconocimiento. En: Polis Revista Latinoamericana, vol.17, nº49. Santiago: Universidad de los Lagos, 201-230.

Meccia, Ernesto (2011). Los últimos homosexuales. Sociología de la homosexualidad y la gaycidad. Buenos Aires: Gran Aldea Editores.

Metz, Christian (1972). El decir y lo dicho en el cine: ¿hacia la decadencia de un cierto verosímil? En: AA. VV. Lo verosímil. Buenos Aires: Tiempo Contemporáneo.

Mitchell, William John Thomas (2014). ¿Qué quieren realmente las imágenes? Yucatán: COCOM.

Moreno, Aluminé (2008). La invisibilidad como injusticia. Estrategias del movimiento de la diversidad sexual. En: Pecheny, Mario; Figari, Carlos; Jones Daniel (Comp.), Todo sexo es político. Estudios sobre sexualidades en Argentina. Buenos Aires: Libros del Zorzal.

Nichols, Bill (2013). Introducción al documental. UNAM, México.

Pecheny, Mario; Figari, Carlos; Jones Daniel (Comp.) (2008). Todo sexo es político. Estudios sobre sexualidades en Argentina. Buenos Aires: Libros del Zorzal.

Scott, Joan (2000). El género: una categoría útil para el análisis histórico. En: Marta Lamas (Comp.). El género. La construcción cultural de la diferencia sexual. México: PUEG.

Traversa, Oscar (2001). Aproximaciones a la noción de dispositivo. En: Signo y seña, $\mathrm{n}^{0} 12$. Buenos Aires: UBA.

Traversa, Oscar (2009). Dispositivo-enunciación: en torno a sus modos de articularse. En: Revista Figuraciones, teoría y crítica de arte, $\mathrm{n}^{\circ} 6$.

Verón, Eliseo (1993). La semiosis social. Fragmentos de una teoría de la discursividad. Barcelona: Gedisa. 
